\title{
EDUCAÇÃO E PATRIMÔNIO CULTURAL: diálogos entre cidade e campo como lugares de identidades ressonantes
}

\author{
Elizabete Tamanini* \\ Zilma Isabel Peixer ${ }^{* *}$
}

\section{Resumo}

Nesse artigo, procura-se delinear as interfaces entre educação popular, patrimônio cultural, campo e cidade, consubstanciados pelas pesquisas em desenvolvimento sobre cultura material e imaterial. Essas reflexões tecem um quadro ainda novo na construção de conhecimento e nos debates na área de Educação, procurando demonstrar a importância dos espaços de memória, entre eles, o museu na construção da pertinência e das identidades coletivas nos movimentos sociais e nas esferas da educação popular. Os fios que buscamos delinear percorrem os caminhos dos modos de vida, dos quais existem poucos registros, daqueles que pouco ou nada aparecem na documentação escrita e na representação da cultura material "oficial". Nossos fios buscam as relações, as tensões, as teias coletivas entre indivíduos, apontando para algumas questões inusitadas que o estudo do patrimônio cultural e o trabalho com educação popular podem nos propiciar.

Palavras Chaves: Educação. Patrimônio. Cidade. Campo.

\section{Introdução: “Educação e Patrimônio Cultural - diálogos possíveis”}

\begin{abstract}
"Um claro sentido da oportunidade histórica, oportunidade que não existe fora de nós próprios, à espera que vamos a seu encalço, mas nas relações entre nós e o tempo mesmo na intimidade dos acontecimentos, no jogo das contradições. História que nos castiga quando não a aproveitamos a oportunidade ou quando simplesmente a inventamos na nossa cabeça, sem nenhuma fundamentação nas tramas sociais" (Paulo Freire, 1997, p. 12).
\end{abstract}

\footnotetext{
* Dra. Em Educação - UNICAMP/SP. Profa. Mestrado em Educação - UNIVILLE/S/Gerente de Patrimônio Cultural/FCJ/Prefeitura de Joinville. E-mail: btamanini2@gmail.com.

*** Dra. Em Ciências Sociais - PUC/SP. Profa. UFSC/SC. E-mail: zilma@cbs.ufsc.br.
} 
As escolhas que fazemos de nosso objeto de trabalho ou de pesquisa nunca são desinteressadas, estão de alguma forma ligadas a nossa história de vida, a valores e princípios ideológicos que se definem ao longo de nossas vidas. A epígrafe do início do texto contextualizado pelo educador Paulo Freire, incita o pesquisador, a pesquisadora a tomar posição diante da história e assumi-la como processo dialético em intimidade constante com as tramas socioculturais. O exercício para o reconhecimento das contradições não significa legitimá-las. Daí a necessidade de interrogá-las continuamente, tendo em vista as heranças sociais as quais foram construídas à história e do mesmo modo, o passado não pode ser utilizado como objeto de dominação para o presente (Benjamim, 1994), assim a reflexão e a ação alimentam-se reciprocamente.

Trabalhamos há algum tempo, quase três décadas, com questões pertinentes ao ato de preservar o patrimônio cultural, relacionando esta problemática a Educação e a Cultura. Nesta escolha esbarramos com linhas e áreas da Educação, bem marcadas por sua trajetória conceitual tendo a educação formal como parte significativa de seus estudos. Práticas e reflexões acerca da educação não formal no Brasil passaram a ter algum destaque na academia, a partir do final da década de 80 do século XX. Assim, pensar patrimônio cultural, participação comunitária, cidade e campo e identidades, significou lidar com a complexidade da Educação como área de conhecimento e ao mesmo tempo tendo uma série de problemáticas de ordem conceitual e multidisciplinar para construir.

Nosso objetivo maior passa pelo aprofundamento das abordagens e diálogos entre educação e patrimônio cultural, movimentos sociais e educação popular, cidade e campo. Todavia, a problemática indiciária tem sido como transformar um museu, lugar de acervos sociais, em um espaço interativo, democrático e pedagógico? Como disponibilizar informações acerca de acervos, saberes, fazeres e conhecimentos para diferentes realidades sociais e para diferentes públicos pertencentes ou não pertencentes ao ensino formal, sem os rótulos e os estereótipos herdados secularmente por instituições da cultura e da educação? Houve sempre uma política de conservação que preservou a casa-grande, as igrejas barrocas, os fortes militares, as câmaras e cadeias como as referências para a construção de nossa identidade histórica e cultural e que relegou ao esquecimento as sensalas, as favelas, os bairros operários, as pequenas comunidades rurais (Funari, 2006). Para tal desafio nos ancoramos nas aprendizagens e experiências vividas com organizações comunitárias, com o movimento social e a educação popular. 
O repensar maduro desse processo teve como repertório conceitual o mestrado e o doutorado que a partir das experiências educativas realizadas, ao logo dos anos, passou-se a estabelecer novas possibilidades teórico-metodológicas. As ligações entre projetos dos movimentos sociais e dos projetos acadêmicos constituem-se em referenciais concretos, permitindo assim, a análise e a sistematização da práxis. Passamos a compreender o significado social da instituição museológica, ao longo dos séculos, o sentido e o significado da construção do conceito de patrimônio cultural, a história da educação, as hegemonias criadas a partir das matrizes curriculares e planos de ensino e, do mesmo modo, aprofundouse a problemática do patrimônio cultural na interface com campo e cidade compreendendo-os como processos em permanente disputa de identidades ressonantes.

\section{Educação Popular, Patrimônio e Herança Cultural}

Como se observa, a temática é abrangente e inesgotável, tanto na discussão, como em polêmica, quanto em pesquisa. E muito há ainda a se fazer nesta trajetória, já que esta problemática vinculada à educação popular e herança cultural compõe um espaço pouco teorizado no Brasil. Conforme Marly Rodrigues (2001) somos uma sociedade que herdou princípios da submissão a escravidão, e desde o inicio da vida colonial houve sempre dois grupos de pessoas no país, os poderosos com sua cultura material esplendorosa, cuja memória e monumentos são dignos de reverência e preservação. E os vestígios esquálidos dos subalternos, dignos de desdém e desprezo.

A Educação é sobremaneira responsável pelo processo cultural, e ainda, pela continuidade ou descontinuidade das estruturas sociais. A Educação está neste caso sendo concebida como um processo sociocultural que carrega em sua gênese um conjunto de práticas, (heranças cognitivas e cognoscitivas) e representações ideológicas. Aqui se preconiza os diálogos e interações entre herança cultural e Educação - diálogo difícil, mas extremamente necessário, considerando os conflitos e percepções libertadoras e limitadoras de ambos os lados. Aspecto esse que não precisamos ir muito longe, somente verificar a estrutura dos poderes públicos municipais no Brasil, nos organogramas institucionais, e daí surge a pergunta, onde se concentram estas temáticas? O desafio é sair do casulo reducionista e cômodo de cada dimensão e observar os diálogos, os pontos de comunicabilidade. Afinal, herança cultural não é somente organização de festas e, educação não é somente reprodução de conteúdos em sala de aula. 
Para as nossas investigações, tais problemáticas constituem elementos indispensáveis para as releituras e reflexões contextuais, onde passado e presente se mesclam na tentativa de elaborarmos discursos de apropriação desses passados e dos significados para a educação. Situamos a reflexão conjugando conceitos de cultura material, memória, museu, educação, herança cultural e cidadania, apontando assim, a complexidade, especialmente, da Instituição museológica na produção de imagens e, sobretudo, a mitificação da memória, que ao se materializar-se em cenários passa a desempenhar um papel estratégico e político. Nesse embate compreende-se com mais intensidade que os museus são locais perigosos! Cada objeto é portador de múltiplos significados, "O museu suprime o tempo e a presença de agentes da história” (Funari, 1995, Tamanini, 1998), e que a cultura material de uma sociedade constitui em si, resíduos do passado e como tal é fonte de relevantes gamas de informações, capaz de oferecer novos e outros tipos de levantamentos e análises dos vários elementos que a integram. Contudo, é através do patrimônio cultural e ou da materialidade humana e das narrativas que se concentra a passagem do tempo, assim a leitura é feita a partir das experiências acumuladas que se desdobram na memória, diante da imagem do presente.

Os passados são sempre construções. Revisitá-los exige compreensão e complexidade. A educação pode contribuir na construção de diálogos, rupturas e confrontos. A comunidade de um dado território não é homogênea, pois é constituída de classes sociais e setores, tais como trabalhadores, trabalhadoras (campo e cidade), como também existem atritos entre os diferentes segmentos (integrados, marginalizados e excluídos). Daí a importância da participação da sociedade nestes processos de leitura e releitura do mundo, na decodificação de seu patrimônio; porque estes elementos reforçariam o seu direito de ser residente, pertencente nesta ou naquela região, neste ou naquele país, com tradições, identidades e culturas distintas e permeiam também a escolha e construção de possibilidades de referências patrimoniais.

Vale destacar que a palavra patrimônio tem diferentes sentidos, mas o que mais significamos é que o uso deste conceito é muito recente na história da preservação, conservação e da Educação. Quando ouvida ou lida esta palavra pode soar para pessoas de diferentes realidades sociais, algo familiar, estranho ou distante da vida cotidiana. Temos observado que muitas pessoas logo associam patrimônio, a coisas herdadas de família, uma herança, um bem imóvel, um valor monetário, um objeto de valor, e, de fato essa relação faz certo sentido. A origem da palavra patriomonium é latim e referia-se, entre os antigos povos romanos, tudo o que pertencia ao pai, pater ou pater famílias, pai de família. Sabemos também que a relação entre estes termos deve ser estudada considerando o contexto social e 
político desse período (idade média). De um modo geral compreendia-se a família incluindo mulher e filhos, como propriedades do senhor. A concepção de patrimônio como um direito coletivo, associado às práticas democráticas populares, nesse momento não existia; ela começa a criar corpus público a partir da revolução francesa.

Nesse sentido, vale uma reflexão sobre o quê de significativo na esfera do público e privado passa a ser reconfigurado e construído a partir de meados de 1700 no contexto da história do patrimônio. A história ocidental começa a definir a ideia de República fortemente associada à redefinição dos Estados Nacionais. A definição de Estado e Nação incorpora, sobretudo, um imaginário de cidadania - com base na idealização de sujeito adulto, portador de direitos e deveres e, portanto, cidadão que necessita compartilhar um território, uma origem, uma língua, uma cultura. Por outro lado, esse "novo cidadão” deve esquecer sua origem particular, sua trajetória humana de diversidade sociocultural para tornar-se morador da cidade, da polis, participando do "desenvolvimento e do progresso" de sua agora, nação. Nota-se que o conceito de nação e cidadão é uma invenção do Estado liberal, e que a noção de patrimônio público associada à coletividade como comentamos no início deste texto, é muito recente na história da humanidade.

A palavra patrimônio, como refletida acima, vem de algo que herdamos paterno e familiar. A partir do século XX a palavra incorpora em sua representação social, relações com processos de preservação e conservação da memória coletiva e de identidade. Vale dizer que a memória e a identidade presentes no patrimônio podem perfeitamente ser negociadas, e não são fenômenos que devam ser compreendidos como essências de uma pessoa ou de um grupo. Isso mostra que a memória e a identidade são valores disputados em conflitos sociais e intergrupais, e particularmente em conflitos que opõem grupos políticos diversos (POLLAK, M. 1989). A criação dos museus nacionais no século XIX e inicio do século XX foi resultado da influência econômica e política na definição do que devia ser preservado, referenciado como patrimônio e que simbolizasse com uma identidade um país, uma nação pensando-a como estratégia de hegemonia social, cultural e política.

O caráter da reflexão neste momento caminha para o sentido e o pertencimento do patrimônio herdado socialmente e do processo de criação no presente. Para quem atua com a história, a identidade e a educação vale recorrer sempre a uma pergunta imprescindível: preservar para que? Ora, os objetos são produtos da ação humana e vetores da ação humana. Todo e qualquer objeto é sempre repositório de uma informação sobre relações entre os seres humanos (FUNARI, 1988). Os séculos XX e XXI, que assistem a consolidação desta nova forma de fazer história e de se compreender a memória, servem de contexto para a ampliação 
do conceito de documento que retira do texto a exclusividade de se caracterizar como tal. Outros suportes, outros indícios, outras formas de expressão, outras fontes, passam a ser valorados como documentos. A imagem trazida por uma fotografia ou um filme, a força emanada de um objeto, a mensagem advinda do som de uma melodia passam a ser merecedores de procedimentos de análise, interpretação, classificação, guarda e conservação. Uma cadeira, por exemplo, é um artefato. É um objeto fabricado pelo ser humano, que encerra vários níveis de informações, especialmente no que concerne aos aspectos tecnológicos, morfológicos e funcionais. Os seres humanos são capazes de construir imagens espaciais elaboradas, que se formam em nosso cérebro, a partir da sua percepção do mundo, voltandose para os interesses das relações existentes entre coisas e as ideias (Amaral, 1998).

Nessa perspectiva, os objetos são dotados de uma significação especial, que faz com que eles representem o "invisível”. Como diz Levi-Strauss (1976), conservado apenas na forma de "registro ou relato, o passado é privado de sua diacronia, quer dizer, o passado passa a existir como fato contemporâneo e recente”, cada vez que é renovado pelas narrativas e práticas rituais. E é justamente na transmissão dos objetos que, segundo o autor referido, as coletividades conferem uma "existência física da história”.

Maurice Halbwachs (1990) nos lembra da importância da leitura dos espaços físicos para a construção da memória coletiva. Este mesmo autor, desde 1920, já havia sublinhado que a "memória deve ser entendida também ou, sobretudo, como algo social, ou seja, um fenômeno construído coletivamente e submetido a flutuações, transformações e mudanças constantes. Além de a memória coletiva se apresentar como tradição, ela se estrutura internamente como uma partitura musical, o que nos possibilita aprendê-la como um sistema estruturado em que os atores sociais ocupam determinadas posições e desempenham determinados papéis.

\section{Educação Popular e Patrimônio Cultural - diálogos ressonantes}

A seleção dos bens preservados quase sempre tem sido efetivada dando-se ênfase aos bens culturais produzidos pelas elites. Em particular, as classes dominantes decidem o que deve ser lembrado e esquecido de acordo com seus desejos e interesses políticos e econômicos, não de acordo com a realidade histórica de cada grupo que constitui a sociedade. Especialmente os museus ainda guardam e preservam formas saudosistas, românticas, elitistas e exóticas de narrar a memória social. Expõe-se, preserva-se algo que está relacionado a um 
passado distante, não há interface com o presente, sendo o cidadão excluído do processo de seleção e da preservação. Nestas instituições oficiais, em grande parte, a herança cultural é representada por legendas e dados lineares como se o patrimônio cultural não estivesse vinculado à história da sociedade enquanto processo e que se ressignifica nas contradições e ressonâncias coletivas de maneira constante.

Ao longo dos séculos os museus vêem passando por inúmeras mudanças. Atualmente tem-se como paradigma que uma das funções mais importante de um museu é a educativa. Estando aberto ou fechado ele comunica, portanto é uma instituição que produz informações, constrói valores e ideologias e a educação como área de conhecimento entraria como ferramenta produtora de diálogos dos saberes e fazeres herdados, acumulados e ressignificados pela sociedade. Nesta direção, há aproximações fecundas com a educação popular, sobretudo ao assumir o caráter social do conhecimento, que para (Freire, 1997) sustenta-se na premissa que a construção é um esforço coletivo, portanto deve ser apropriado criticamente permitindo os usos para a transformação social.

Tais reflexões e experiências acirraram as contradições provocando ruídos em instâncias estruturais e teóricas. É nesse contexto que as provocações formuladas por Freire (1997) e Benjamim (1994) especialmente quando discutem o conceito de história e experiência, que se compreendem as peculiaridades dentro de um contexto de totalidade, recuperando a dimensão política da preservação e a participação popular. Assim nossas premissas básicas para os projetos voltados a museus e espaços comunitários de memória convergem para a construção de diálogos emancipatórios.

Nesse sentido as ações passam a ser pensadas em contextos e processos permanentes tentando não cair nas armadilhas dos arranjos metodológicos construídos pela educação formal de cunho neoliberal. Até porque essas instituições atuam com educação, mas não pertencem à categoria do ensino formal, tampouco podem se transformar em um laboratório da Escola. Para Lopes, a contribuição dos museus à educação "não deveria ser tratada prioritariamente apenas do ponto de vista de enriquecer, complementar currículo, ilustrar conhecimentos teóricos, tampouco a partir de propostas de intervenção direta no processo educacional formal, que dificilmente se comprometeriam com o “desempenho" das sequências longas e rotineiras da aprendizagem escolar (apud Tamanini, 1998, p. 205). Os museus ainda sobrevivem em consequência do número de estudantes que os visitam. A relação pedagógica em grande parte se dá na perspectiva de uma “visita”, sem comprometimentos processuais acadêmicos para as instituições envolvidas - Escola e Museu. 
“Os objetos não falam por si só”. Só os codifica quem tem os códigos e os signos para os fazê-los.

Por um lado, neste repensar teórico-metodológico deu-se inicio no final da década de 90, século XX, em algumas instituições do país, a criação de programas de educação em museus, onde a problemática residia na formação de professores, formação de público e participação comunitária. Estas ações contemplavam linguagens educativas singulares a museus, a espaços de memória e ao campo teórico da educação popular inspirada na pedagogia de Paulo Freire. Por outro lado, no final da década de 80, ainda grande parte das instituições de cultura e educação no país se negavam a pensar em educação popular, ou assumirem as inspirações Freirianas de Educação. Muitos secretários e secretárias de educação ou cultura mencionavam e citavam sua influência pedagógica, mas tampouco, enquanto representantes das políticas públicas assumiam como proposta político-pedagógica. Segundo Fleury (2002, p. 57):

Numa sociedade capitalista, a educação popular, propriamente dita, opõe-se às diferentes formas de intervenção educativa realizadas pelas agências da classe dominante junto às camadas populares. Constitui-se como o conjunto de processos educativos desenvolvidos pelas classes populares em suas lutas pela construção de sua hegemonia e de sua resistência à exploração e a dominação capitalista.

Tratando-se da cultura, o afastamento era ainda maior. Observa-se fortemente esse distanciamento quando no final da década de 60 e inicio de 70, o Programa Nacional de Museus passa a adotar como linha de ação os pressupostos teóricos da Educação permanente definidos pela UNESCO. "Os projetos de educação de adultos, patrocinados pela UNESCO (United Nations Education Social And Cultural Organization) a partir da década de 40 em diante, servem como instrumento para a burocratização dos trabalhos anteriores de educação junto ao povo, centralizando-os, ampliando-os e rotinizando-os sob o controle do Estado (Fleury, 2002, p. 55). No caso do Brasil, os museus e centros culturais não assumiram as propostas de Educação Popular. Estiveram ausentes, não participaram ativamente dos movimentos de educação e cultura deflagrados nas décadas de 70 e 80 . Preferiram adotar as concepções de Educação Permanente e de Educação Patrimonial, “importadas” para o país, o que reduziu em muito, as práticas educativas em museus à complementariedade da Escola. 


\section{Patrimônio Cultural, Cidade e Campo: a educação popular na produção de diálogos ressonantes}

Quando afirmamos que nossa atuação frente ao mundo não é desinteressada e tampouco o conhecimento é disciplinar, contextualizamos estas reflexões tendo como pressuposto a nossa experiência profissional e acadêmica ao longo desses anos atuando com educação. Nessa construção passamos a observar fortemente o quanto no Brasil as pequenas comunidades, aquelas mais afastadas dos centros urbanos, são desprovidas das condições elementares à qualidade de vida. Afora as desigualdades sociais mais prementes, parte das memórias, das histórias de vida, ou seja, o patrimônio cultural vivo e presente nessas comunidades estão depositados e "tombados" em muitos museus já estudados em nossas pesquisas como acervos antigos, coisas do passado.

Novamente refletimos o quanto os museus negligenciam a cultura como um fenômeno social dinâmico, tratam do passado pensando nos objetos, nas “coisas velhas”. A sociedade, o ser humano, os saberes, os fazeres, as identidades, a vida estão ausentes da produção e do significado da cultura, seja ela material ou imaterial - passado e presente - não são passíveis de contextualização. Nas trajetórias construídas e das temáticas estudadas, como patrimônio, memória, educação e herança cultural, dos espaços sagrados e protegidos da Escola e do Museu, nosso olhar tem percorrido o "sertão", o "sertão da serra catarinense, os lugares afastados e ausentes das infraestruturas públicas onde em algumas situações o ir significa fazer a trilha a pé ou em lombo de cavalo. Segundo Peixer (2002) com as mudanças socioculturais ocorridas nas últimas décadas nessa região, de modo substancial com o êxodo rural, "há que se considerar, que a vinda para cidade não significa a ruptura completa com o modo de vida anterior e com a cultura política engendrada nas relações entre fazendeiros, peões e agregados, isto tem repercussões nos processos de organização dos grupos locais e sua efetiva participação em movimentos sociais.” um processo de ressignificação dos antigos valores, em que as relações paternalistas com os fazendeiros se reelaboraram em postura eivadas de clientelismo com o poder público local”.

Moraes Pessoa (2005, p. 51) contribui com a análise quando contextualiza que estas relações, de identidades e posturas diante do mundo não desaparecem por conta de mudanças territoriais, segundo esse autor, "temos uma intersecção entre campo e cidade, em diversas manifestações e formas. O que marca as ruralidades é a relação com a terra, com o plantar. Isso faz parte, está presente em nossos processos de construção de identidades. Há 
muitas pessoas que morando em médias e grandes cidades elaboram sua compreensão de mundo com as referências do mundo rural”.

Assim a reflexão fundamenta-se nas pequenas comunidades rurais, no inventário das identidades culturais, sociais e políticas, tendo a memória e a cultura material e imaterial presentes como tema gerador e a educação popular como paradigma de mediação e diálogos. As antigas igrejas, as antigas escolas isoladas, os salões paroquiais, os saberes e os fazeres das comunidades poderão de todo modo ser escavados, e quiçá escovados a "contrapelo da história como diz Walter Benjamim”.

A investigação caminha para a produção acadêmica mais recente no Brasil sobre está temática. O significado social da educação em pequenas comunidades rurais, o papel das referências patrimoniais identitárias na construção e desconstrução de conhecimentos e saberes comunitários, as identidades, a dinâmica social produzida pelo sentido da escola, da igreja, dos lugares de memória como ressalta LE Goff e Nora, (1979, p.13):

(...) "trata-se no sentido preciso do termo em que uma sociedade qualquer que ela seja, uma nação, uma família, uma etnia, ou um partido, encerram voluntariamente as suas recordações e as reencontram como parte necessária da sua personalidade: os lugares topográficos, como os arquivos, bibliotecas e museus; os lugares monumentais, como cemitérios ou o patrimônio construído, os lugares simbólicos, como as comemorações, as peregrinações, os aniversários ou emblemas; os lugares funcionais, como os manuais, as autobiografias ou associações. Mas fazer história conduz a mudar o sentido da própria palavra, passando da memória dos lugares aos verdadeiros lugares da memória.”

Sabemos que faz sentido neste momento incluirmos este tema para uma releitura sobre os caminhos da educação popular e do significado da preservação do patrimônio cultural para as pequenas comunidades campesinas/rurais. Paulo Freire, (1996: 100) afirma que "a Pedagogia é uma reflexão crítica sobre os quefazeres humanos. Para melhor realizarse, estes quefazeres buscam a compreensão científica do mundo. A Pedagogia precisa das ciências e, através destas, acontece como reflexão crítica (...) uma ciência é um campo de conhecimentos e procedimentos que tem autonomia epistemológica. Tem, também, uma certa autonomia classificatória (taxonômica) em seus procedimentos e na sua conceituação. Ela é autônoma, embora relacionada com outras ciências”.

Temos estudado e acompanhado uma série de pesquisas e experiências fundamentadas nos princípios da educação e grande parte dos enfoques estão voltados para as áreas mais convencionais da educação e da cultura. Segundo STRECK (2006, p. 272) “Dois fatos contribuíram para definir os rumos da educação popular nestas últimas décadas: foram - 
a ida de Paulo Freire à Secretaria de Educação na cidade de São Paulo de 1989 a 1991 e a conquista do poder local por governos que assumiram uma proposta de educação popular”. “A educação popular passou, assim a aproximar-se do lugar onde se gera o discurso pedagógico hegemônico, com todas as vantagens e riscos”.

Nesse sentido, nossas investigações passam pelo viés da herança cultural, conceito e significado de extrema relevância para a emancipação social. O que é preservado? O que se solidifica? O que se destaca e é alçado ao papel de baluarte da memória e da história? E que ao mesmo tempo pode servir de espaços de pertencimento de identidade, e também de espaços de mudança, ou seja, que propiciem a reflexão critica sobre o ser humano e sua comunidade. Mas neste caso, o que é premente é o problema das relações humanas. Em toda resposta que o ser humano dá existe a presença das experiências anteriores, a ação da memória. Toda ação humana é uma ação com carga de memória e se não houvesse memória, a cultura não seria possível. "Como o indivíduo universal, o cidadão do mundo poderia orientar-se na cidade, no campo, quando sua geografia está presa à memória? Isto é, quando devemos recordar que a Rua da Fonte não possui nenhuma fonte e termina na rua das flores, as quais, por sua vez faz tempo que não exalam cheiro”. (Lovisolo, 1989, p. 19). Além de a memória coletiva se apresentar como tradição, ela se estrutura internamente como uma partitura musical, o que nos possibilita aprendê-la como um sistema estruturado em que os atores sociais ocupam determinadas posições e desempenham determinados papéis.

Ao trabalharmos com o patrimônio cultural buscando compreensões acerca da herança cultural no próprio seio das comunidades históricas, as maneiras como elas "viveram e vivem o seu passado, como constituem sua memória coletiva e como esta lhe permite fazer em face dos acontecimentos presentes, percebemos que estes elementos não são somente uma conquista, mas também instrumentos e objetos de poder” (Khoury, 1991, p. 81). O sistema capitalista vê essas questões como algo sem importância, alicerçado no paradigma do processo produtivo do campo em decadência, excluindo as comunidades de qualquer possibilidade de resistência ou sobrevivência social e cultural.

Historicamente, com o desenvolvimento do capitalismo, o camponês é condenado ao desaparecimento, à proletarização, à transformação em operário. Na relação com o camponês, o que o capital faz é tentar separá-lo dos meios de produção, convertê-lo em força de trabalho para o capital. (Martins, 2002, p. 83-84).

Vale ressaltar, que a valorização e estimulo à participação da sociedade na discussão sobre a preservação do patrimônio cultural não exime a responsabilidade do Estado. 
Não deixar se trair pelos ventos do neoliberalismo da participação esvaziada significa rever constantemente o complexo processo histórico e econômico em que o Brasil está inserido.

O Campo brasileiro, o meio rural, especialmente no século $\mathrm{XX}$, passou a ser considerado e visto como área marginalizada, uma vez que o discurso clássico da "modernidade" apoiou-se no modelo industrial, privilegiando a cidade como ideal de desenvolvimento, num processo hierarquizador desses lugares, onde, por um lado, o campo passou a exercer o papel de saneador das necessidades urbanas (fornecimento de matériaprima, alimentos, água potável, reservas de valores, especulação imobiliária, entre outros exemplos). Tal estratégia resultou no retardamento - e em alguns casos, até mesmo na atrofia - do movimento na construção e promoção do desenvolvimento social e da conquista de uma melhor qualidade de vida. Segundo Bosi, (1994, p. 11). "As palavras cultura, culto e colonização derivam do mesmo verbo latino colo, cujo particípio passado é cultus e o particípio futuro é cultus. Colo significou, na língua de Roma, eu moro, eu ocupo a terra e, por extensão, eu trabalho, eu cultivo o campo. Cola é a matriz da colônia enquanto espaço que esta ocupando, terra ou povo que se pode trabalhar e sujeitar”. Ao campo foi reservado, no processo capitalista, primeiro à função de colonizar e agora consumir os serviços e produtos oriundos das cidades, num comportamento eminente passivo diante do projeto neoliberal. Porém, a realização de dimensões da essência humana é possibilitada, entre outras coisas, pelos artefatos criados pelo trabalho humano, do homem para o homem, numa escala cada vez mais histórica.

Não só no Brasil, como em muitos outros países, este modelo que com nuances diferentes de urbanização provocou o esvaziamento das áreas campesinas resultando não só em graves problemas sociais e culturais para o meio rural, como também para a cidade. Ao viverem um momento de transição, os trabalhadores acabavam por não usufruir de "novos direitos” nem eram desobrigados de "deveres antigos”. O campo passou a depender cada vez do Estado/governo para poder manter-se produtivo. Todavia, os recursos para manter as atividades da agricultura familiar são insuficientes para assegurar a produção e a qualidade de vida da população do campo que vivencia, ao longo dos tempos, dolorosas escassez dos mais elementares recursos de subsistência. Segundo Martins (1986, p.146):

Na verdade, o que os grandes estabelecimentos estão claramente produzindo, ao manter, especulativamente, terras incultas em alta proporção, é renda fundiária e não lucro nem riqueza ou maior valor de produção. Estão interessados na elevação especulativa do preço da terra e na renda fundiária que daí resulta sem necessidade de maiores 
investimentos de capital. (...) A explicação não é completa nem correta se deixarmos de lado o fato de que a grande produção na agricultura, assim como a pequena, envolve a renda fundiária e a contradição que a renda apresenta na produção capitalista.

Assim, as comunidades campesinas/rurais no Brasil veem sofrendo processos de desestruturação nas diferentes dimensões. Nas últimas décadas, os apelos, para as ditas mudanças socioculturais, foram forjados à luz do modelo econômico neoliberal que abstrai das experiências comunitárias a ideia de que os sujeitos são algo em si, quando identificados ao consumo extremo. As Escolas, a partir de seus Programas de Ensino, acabam por legitimar esse modelo, que nega a possibilidade de resistir a violência do mercado. Tal legitimidade e/ou tal autonomia “é produzida no momento em que se faz uma separação entre indivíduos que dominam e as ideias que dominam, de tal modo que a dominação de homens sobre homens não seja percebida porque aparece como dominação das ideias sobre todos os homens” (Chauí, 1981, p. 106). Ressaltamos o papel da Escola porque para os pequenos lugares, pequenas comunidades a Escola exerce um papel essencial na construção de relações societárias, e identitárias interagindo com diferentes grupos sociais.

Não podemos falar só daqueles que frequentam a educação formal, mas também nos que vão se educando informalmente junto da sua família, constituindo, por vezes, a sua memória coletiva, com as memórias dos outros, inventando, criando um imaginário que os equilibra face ao desenraizamento que sofrem. Sobretudo o que se observa a partir de pesquisas sobre currículo e conteúdo programático para as escolas do campo e das inúmeras escolas rurais, igrejas e outros elementos de identificação abandonados no Brasil (cultura material - patrimônio cultural das comunidades), é que a referência e o modelo ideológico de sociedade fundamentam-se num imaginário urbano-capitalista.

A moeda da cidadania, da inclusão passou a ser o cartão de crédito, porém, cidadania é vivida por aquele que mora na cidade. Quem vive nas áreas rurais ou vive do campo, pouco pode ter acesso aos bens produzidos e ofertados na polis, portanto a cidadania é restrita. A problemática fundamenta-se não na acessibilidade, mas nas ideologias de apropriação e valoração destes processos. Para ORTIZ (1996), a sociedade brasileira, passa nesse momento, também, por uma reorganização na esfera da cultura. "Sobretudo com a consolidação, nos anos 60 e 70, das indústrias culturais”. As diferenças entre o que se ensina para as comunidades rurais e as comunidades urbanas, neste modelo, referem-se ainda a um projeto desenvolvimentista ancorado em estereótipos. O fazer e o saber das comunidades rurais 
podem se transformar em algo importante ou exótico (falamos das experiências de turismo no espaço rural) quando o “modelo” se apropria destas singularidades para o consumo urbano.

As teorias críticas têm contribuído para aumentar nossa compreensão sobre as íntimas e estreitas relações entre conhecimento, poder e identidade social e, portanto, sobre as múltiplas formas pelas quais os conhecimentos e saberes estão centralmente envolvidos na produção do social. As teorias da reprodução social, por exemplo, nos mostram como as distribuições desiguais de conhecimentos, através da matriz curricular da escola e dos museus, constituem mecanismos centrais do processo de produção e reprodução de desigualdade social. A Educação, em um quadro mais estrutural, tem sido efetivada a partir da seleção autoritária, burocrática, inadequada e imposta dos saberes.

A Educação, a partir da interface com a Escola, detém responsabilidades tanto de manutenção deste modelo como poderá ser produtora de rupturas no campo do fortalecimento das identidades e das diferenças, tendo a produção humana como convergência entre identidades, comunidades e saberes. Todavia, como um modo de existência ímpar, como um referencial capaz de “juntar fragmentos” e forjar a "identidade mestra” (Hall, 2003).

E essa é uma rede de diversos pontos nodais, em busca do entendimento desses processos e atuação articulada, que possam contribuir para a autonomia das sociedades, que em síntese é que o Paulo Freire tanto destacou a "luta contra todos os obstáculos a humanização [do individuo]”. E esse é um ponto chave, construir um presente e um futuro melhor de forma igualitária, mesmo porque estamos na eminência da insustentabilidade humana.

E aí chegamos a outro grande impasse, percebemos que a cultura se transforma também no grande apanágio, tanto para justificar a permanência e imutabilidade das condições e estruturas sociais como para servir de vetor para essas mesmas mudanças. É só observarmos os discursos sobre desenvolvimento e sustentabilidade social. Isso nos remete a pontos que gostaríamos de abordar, que é sobre os elementos de permanência cultural, e, aqui considerando em dois aspectos: de dominação e de resistência/autonomia.

Memórias, subjetividades, identidades, heranças culturais formação do sujeito individual e coletivo, submersos na dimensão cultural. Muitas vezes não entendemos os liames e os fios que formam essa trama, e o discurso da cultura tanto pode servir para camuflar e justificar como para desvelar e romper. Memórias e heranças culturais escondidas e camufladas, mas que formam parte significativa do território cognitivo de atuação social.

Assim, lembramo-nos das práticas do coronelismo, que enquanto sistema político, já foi superado, mas enquanto prática política cotidiana está muito vivo nas práticas políticas e 
relação entre grupos sociais e Estado, onde espaços e instrumentos de relações democráticos, como: eleições diretas, informatizadas ou audiências pública são rearticuladas nas práticas de mandonismo local, onde o momento em si (eleição, assembléia) e seus coadjuvantes o churrasco, a camiseta, o boné, a cesta básica, a caneta, formam uma intrincada rede de submissão e reafirmação do sistema autoritário e hierárquico local. E que reafirmam também a relação de dependência/clientelismo para com o Estado. Aspecto que continua contribuindo para as estruturas desiguais da sociedade. Referencias culturais como esses dimensionam tempos e movimentos, e constituem-se em referenciais das práticas sociais, especialmente em pequenas comunidades rurais. A escola vai funcionar e a igreja ficará onde está se "eles os donos do poder”, se assim os desejarem.

Saber as formas de vida as quais existam poucos registros, saber como os silenciosos, aqueles que pouco ou nada aparecem na documentação escrita e na representação da cultura material "oficial” - museus, centros de memórias e territórios de referências - saber como encarar sua existência diante das modificações tão rápidas em curso, buscar as relações, as tensões, as teias coletivas entre indivíduos num grupo numa camada social em épocas distantes e também agora, de pessoas que experimentam mudanças, segundo valores já preestabelecidos, de normas e comportamentos que aceitam ou rejeitam, são algumas questões inusitadas que o estudo da cultura material e o trabalho com educação popular pode nos propiciar.

Vale dizer que identidade e herança cultural podem perfeitamente ser negociadas, e não são fenômenos que devam ser compreendidos como essências de uma pessoa ou de um grupo. Se é possível o confronto entre memória individual e a memória dos outros, isso mostra que a memória e a identidade são valores disputados em conflitos sociais e intergrupais, e particularmente em conflitos que opõem grupos políticos diversos.

Desejamos decidir coletivamente o que queremos e o que devemos preservar como patrimônio. Não são somente, os donos do poder, os técnicos, os cientistas que detêm as condições estruturais e tampouco os museus os únicos espaços legítimos para escolha e recolha do que deva ser patrimônio. Quando pensamos sob uma perspectiva dialógica (FREIRE, 2006), recorremos ao conjunto das representações sociais para o estabelecimento de negociações construindo a priori a possibilidade de se optar a respeito das memórias, das identidades que significam o patrimônio social a ser conservado e preservado. Sejam estes elementos forjados em espaços criados oficialmente, como os tradicionais museus, ou também espaços com novas concepções de cuidado, seleção e socialização do Patrimônio como “casa de cultura”, “espaço de referência comunitária”, “museu vivo”, “eco-museu”, 
“museu comunitário”, “museu integral”, “centro cultural, “estação de memória”, “arquivo de Referência da cultura popular”, "planetário a olho nu” e muitas outras experiências que contribuem sobremaneira nas reflexões destas problemáticas contemporâneas.

Estes espaços poderão representar a memória, a identidade e a cultura da comunidade onde estão inseridos. Sugerem a produção de diálogos entre saberes e fazeres do passado e do presente. Como movimentos sociais em permanente reflexão promovem rupturas e contribuem com a educação entendida numa dimensão humanista. O patrimônio representado na cultura material e simbólica é resultado de um processo histórico, político e social. Ao longo dos séculos foram os museus e centros culturais que assumiram para si a concepção de conservação do patrimônio. Entretanto, os museus como observamos nas narrativas deste texto vêm passando por inúmeras mudanças. Hoje compreendemos que uma das funções mais importantes de um museu, de um centro de memória ou de uma biblioteca, é a educativa. Estando abertas ou fechadas estas instituições transmitem informações, comunicam. Portanto, são instrumentos de formação, constroem valores e ideologias, e a educação como área de conhecimento entraria como ferramenta produtora de diálogos dos saberes e fazeres herdados, acumulados e ressignificados permanentemente pela sociedade.

Já é de conhecimento público que a instituição museológica não é mero depósito de coisas velhas. Esta instituição é responsável pela conservação, preservação e divulgação do patrimônio herdado socialmente. Presenciamos, em meados do século XX e inicio do XXI, mudanças importantes na releitura do significado do patrimônio histórico. A centralidade das reflexões passa a permear a ideia de cultura como elemento fundante. Tais questões estão sustentadas no reconhecimento da diversidade cultural, das inúmeras experiências societárias no mundo, das desigualdades e diferenças no enfrentamento do desafio de pensar sobre o que é cultura, identidade, preservação, conservação, memória e patrimônio em cada território, lugar, região, país e nação.

A Pesquisa científica e as abordagens reflexivas têm sido fundamentais para a construção de novos conhecimentos a partir dos acervos que os museus, centros de memórias, bibliotecas e escolas possuem ou escolhem como tema gerador de sua função social. Para o educador e ainda estimulador da pedagogia museológica dos Ecomuseus, na França e no Canadá, Paulo Freire, (1997) “a Pedagogia é uma reflexão crítica sobre os quefazeres humanos. Para melhor realizar-se estes quefazeres buscam a compreensão científica do mundo. A Pedagogia precisa das ciências e, através destas, acontece como reflexão crítica (...) uma ciência é um campo de conhecimentos e procedimentos que tem autonomia epistemológica. Tem, também, uma certa autonomia classificatória (taxonômica) em seus 
procedimentos e na sua conceituação. Ela é autônoma, embora relacionada com outras ciências” (TAMANINI, 2001).

Os programas de Educação em museus podem estimular e contribuir ainda mais para a aproximação da comunidade com esta instituição, desmistificando este ambiente. Os museus ou "lugares de memória” da atualidade deverão buscar a qualificação nas diferentes dimensões institucionais. Como instituições comunicadoras, poderão construir projetos e ações que mobilizem a sociedade de um modo geral. Para tanto, é necessário convergir para Programas multidisciplinares envolvendo muitos profissionais para a execução de seu trabalho. A essência presente no trabalho de conservação e preservação do patrimônio é a vida, sobretudo investiga-se através do patrimônio a vida dos seres vivos, portanto, espaços de memórias são lugares de vida, e não de morte.

A criação de linguagens que representem o processo de desenvolvimento crítico do ser humano - princípio da educação - Educação compreendida além dos muros formais da Escola e dos Museus. Tal desafio exige um exercício de tolerância (FREIRE, 2006) que na perspectiva Freiriana revelaria em diferentes realidades estudadas, descobertas de temas problematizadores comuns. Observando por exemplo, o trabalho das Escolas e o trabalho das instituições de patrimônio nas suas relações com o ato de socializar e educar sobre o conhecimento produzido e a produção de novos saberes para diferentes realidades socioculturais.

A Escola trabalha essencialmente com memórias, saberes, identidades, patrimônios herdados, acúmulos sociais representados fortemente pelos conhecimentos repassados em seus conteúdos programáticos, pelos cadernos que cada estudante vai guardando de ano a ano após concluir uma série ou período. Tematizar e problematizar estas questões significando-as e ressignificando-as em sua interface com o presente é um dos princípios filosóficos da educação Freiriana e da educação patrimonial. Muitas escolas brasileiras vêm realizando um trabalho valioso nesse sentido.

Nossa intenção foi nos provocar enquanto profissional que atua em instituições que carregam secularmente estereótipos e modelos. Ao mesmo tempo, provocando também o ensino formal para a construção de novos diálogos entre o que se ensina na Escola e o que se podia aprofundar e interagir com um trabalho sistematizado entre estas instituições, cujo tema gerador é a nossa “condição humana”. Paulo Freire (2006) fala que a educação deve gerar um processo dialógico entre os sujeitos que ensinam e entre os sujeitos que aprendem. Assim, a valorização do patrimônio só será compreendida e assumida socialmente quando construirmos com mais intensidade relações democratizadoras em nossas instituições culturais e educativas. 
À medida que a sociedade tiver espaço de formação, participação, ela saberá optar e decidir sobre o significado de preservar a sua memória, a sua identidade e a sua história.

Nos países da Europa se definiu há décadas políticas públicas para o patrimônio e com recursos financeiros permanentes. Por outro lado, o sentido filosófico da preservação do patrimônio social passa pelos debates e conflitos que "nosotros" vivemos no Brasil e na America Latina. Vêm se realizando ao longo dos anos debates e fóruns nacionais e internacionais que tem levado a construção de parcerias e ações que transcendem países, territórios e regiões e a nosso ver significa um grande passo para a democratização dos patrimônios sociais construídos pela humanidade.

Pode se afirmar que avançamos qualitativamente na definição de políticas públicas de preservação nestes últimos tempos. No Brasil a criação do Sistema Nacional de Museus, 2004 (MinC, 2005), a instalação de Fóruns, sistemas estaduais e redes municipais em muito têm contribuído para o debate em torno desta problemática. Todavia, precisamos avançar na formação dos profissionais que atuam nestas aéreas imprescindíveis a qualidade de vida do planeta. Há ainda grandes vácuos no investimento da qualificação estrutural das instituições que atuam com o patrimônio e a educação. Temos muitos museus e centros de memórias que são somente depósitos de coisas velhas. E muitas escolas que continuam com muitos estudantes nas salas de aulas, contudo sem compreender o sentido de apreender e educar-se. Concluem a educação básica sem saber ler e interpretar, portanto não saberão "ler o mundo” (Freire, 1997). E para esses novos tempos, não se pode mais admitir tamanha disparidade entre um conceito de instituição que preserva pesquisa, comunica e divulga, para um conceito de "depósito". Ou de uma postura educativa centrada na condição de receptores de conhecimentos já reproduzidos pela humanidade - a condição "bancária do ensino” e sim, para o desafio da problematização de ler o mundo para poder transformá-lo. Parafraseando um ditado popular em que se diz que “o tempo é o melhor remédio”, todavia, este tempo também é relativo como se discutiu no texto, e pode ser cristalizado, revisitado, revisado e construído, portanto é sempre perigoso! Como diz Paul Valery (1998):

\footnotetext{
“A história é o mais perigoso produto fabricado pela química do intelecto. Pois suas propriedades são capazes de produzir os acontecimentos ou impedir que eles sejam produzidos. Fazem sonhar, embriagam os povos, engendram nelas falsas lembranças, exageram seus reflexos, conservam suas velhas feridas, atormentam-nos no seu repouso, conduzem-nos ao delírio de grandezas ou de perseguição, tornam as nações amargas, soberbas, insuportáveis e vãs” (p. 23).
} 
Desse modo, o que fomos no passado e o que somos hoje depende da compreensão que se tem sobre a história. A construção da identidade é um fenômeno que se produz em referência aos outros, em relação aos critérios de aceitabilidade, de admissibilidade, de credibilidade e que se faz por meio de negociação direta com os outros. Somos seres humanos e nossa eterna referência será o “outro”, só assim somos alguém neste planeta finito.

Por fim nossa metáfora parte de um ditado popular, “Água mole em pedra dura tanto bate até que fura”, retomando desse modo a contradição, o desagravo e a resistência às condições históricas cravadas pelo tempo, neste caso negando a ideia de que ele é o melhor “remédio”, pois o tempo também é relativo e pode ser cristalizado, revisitado, revisado e (re) construído, construído, na perspectiva do diálogo e da ressonância das contradições sociais

\title{
Education and cultural heritage: town and country as identity settings
}

\begin{abstract}
The paper aims at relating popular education, cultural heritage, town and country, putting together studies on material and intangible culture aspects. It also aims at contributing to fostering innovative practices and knowledge about memory settings, such as museums, including social movements and popular education. The paper also addresses concepts such as ways of life, sometimes forgotten and almost invisible in the mainstream documents and "official" material culture collections and exhibitions. The paper then explores relations, contradictions and a plethora of collective and personal exchanges, showing how unexpected issues relating to heritage and popular education can prove useful and fruitful.
\end{abstract}

Key words: Education. Heritage. Tow. Countryside.

\section{Referências:}

ABREU, R. \& CHAGAS, M. Memória e Patrimônio. Ensaios Contemporâneos. Rio de Janeiro: DP\&A, 2003.

AMARAL, Dulce Vidigal do. A cartografia a serviço do imaginário no tempo e no espaço. In: Espaço e geografia. Ano 2, n. 1. Brasília: Instituto de Ciências Humanas, Universidade de Brasília, 1998.

BENJAMIM, W. Sobre o conceito de História. In: Magia e Técnica, Arte e Política: ensaios sobre literatura e cultura. São Paulo: Brasiliense, 1994.

BOSI, Alfredo. Dialética da colonização. São Paulo: Cia das Letras, 1994.

CALVINO, Ítalo. As Cidades Invisíveis. São Paulo: Cia das Letras, 1998. 
CHAUI, M. O que é ideologia. São Paulo: Brasiliense, 1981.

FALKEMBACH, E. M. F. Socialização e Individuação. Ijui: Fronteiras da Educação/UNIJUI, 2006.

FERNANDES, J.R. Educação Patrimonial e Cidadania: uma proposta alternativa para o ensino de História. Revista Brasileira de História, 13, 1993.

FREIRE, P. Pedagogia da esperança: um encontro com a pedagogia do oprimido. 3. ed. São Paulo: Paz e Terra, 1997.

Educação e mudança. Rio de Janeiro: Paz e Terra, 1983.

FREIRE, P. Pedagogia da Autonomia. São Paulo: Paz e Terra, 1997.

Terra, 2006. . Pedagogia da Tolerância. São Paulo: Paz e

FUNARI, P. P. A. ORSER,C. E. Jr, SCHIAVETTO, S. N. O. (Orgs.) . Identidades, discurso e poder: estudos da Arqueologia contemporânea. 1. ed. São Paulo: Annablume, 2005.

FUNARI, P. (Org.) Cultura material e arqueologia histórica. Campinas: São Paulo, UNICAMP. F.C.H., 317 p. (Coleção Ideias), 1998.

FUNARI, P. O papel da cultural material urbana na construção de uma memória histórica. In: Cidade e Memória. Porto Alegre: Prefeitura Municipal, 1995.

HABWACHS, M. A memória coletiva. São Paulo: Vértice, 1990.

HALL, S. Da Diáspora: identidades e mediações culturais. In: Liv Sovik (Org) Belo Horizonte: EdUFMG, Brasília, UNESCO, 2003.

LE GOFF, Jaques; NORA, Pierre. História novos problemas. São Paulo: Francisco Alves, 1979.

LEVIS-STRAUSS, C. O pensamento selvagem. São Paulo: Nacional, 1976.

LOVISOLO, Hugo. A memória e a formação dos homens. In: Estudos históricos. Rio de Janeiro: Vértice, 1989.

MARTINS, J.S. A sociedade vista do abismo: novos estudos sobre exclusão, pobreza e classes sociais. Petrópolis: Vozes, 2002.

Paulo: Hucitec, 1986.

A reforma agrária e os limites da democracia na "Nova República”. São

Ministério da Cultura. Política Nacional de Museus. Departamentos de Museus e Centros Culturais. Relatório de Gestão 2003/2004. Brasília- MinC/IPHAN/ DEMU, 2005.

ORTIZ, R. A Mundialização e Cultura. São Paulo: Brasiliense, 1996. 
KROURY, Y. A. Documentos orais e visuais: organização e usos coletivos. In: REVISTA DO ARQUIVO MUNICIPAL. Memória e ação cultural. São Paulo: Departamento do Patrimônio Histórico, 1991.

PEIXER, Z. I. A cidade e seus tempos: o processo de constituição do espaço urbano em Lages. Lages: Ed. UNIPLAC, 2002.

PESSOA MORAIS, J. Saberes em Festa. Goiânia: Kelps/UCG, 2006.

POLLAK, Michael Memória, esquecimento, silêncio. In: Estudos Históricos (3), Memória. São Paulo: Vértice, 1989.

RODRIGUES, M. Preservar e Consumir: o patrimônio histórico e o turismo. In: Turismo e Patrimônio Cultural, P.P.A. Funari\& J. Pinsky (Orgs), São Paulo Contexto, 2001.

TAMANINI, Elizabete. Museu Arqueologia e o Público. In: FUNARI, P.(Org.) Cultura material e arqueologia histórica. Campinas: São Paulo, UNICAMP. F.C.H., 317 p. (Coleção Ideias), 1998.

TAMANINI, Elizabete. Vidas transplantadas: museu, educação e a cultura material na (re) construção do passado. Tese de Doutorado. Universidade Estadual de Campinas/SP: Faculdade de Educação, 2000.

TAMANINI, Elizabete; GRUN, Mauro; PEIXER, Zilma, I. Desertos Verdes e Azuis. In: BRAVO, Álvaro. Ciudades, Medioambiente \& Sostenibilidad. Sevilla: ArcBel. 2007.

TAMANINI, Elizabete; PEIXER, Zilma I. Turismo, Cultura e Identidade - a interface com os museus e a educação patrimonial. SEABRA, Giovanni (org). Turismo de Bse Local: Identidade cultural e desenvolvimento regional. João Pessoa: UFPB ed., 2007. 